\title{
Comparison of echocardiography and angiography in determining the cause of severe aortic regurgitation
}

\author{
NICHOLAS L DEPACE, PASQUALE F NESTICO, MORRIS N KOTLER, GARY S MINTZ, \\ DEMETRIOS KIMBIRIS, INDER P GOEL, E ELAINE GLAZIER-LASKEY, JOHN ROSS \\ From the Likoff Cardiovascular Institute, Hahnemann University, Philadelphia, Pennsylvania, USA
}

SUMMARY To assess the accuracy of echocardiography in determining the cause of aortic regurgitation $M$ mode and cross sectional echocardiography were compared with angiography in 43 patients with predominant aortic regurgitation. Each patient had all three investigations performed during the same admission to hospital. In each instance, the cause of aortic regurgitation was confirmed at surgery or necropsy. Seventeen patients had rheumatic aortic valve disease, 13 bacterial endocarditis with a perforated or partially destroyed cusp, five a biscuspid aortic valve (four with a history of endocarditis), and eight aortic regurgitation secondary to aortic root dilatation or aneurysm. Overall sensitivity of echocardiography and aortography was $84 \%$ in determining the cause of aortic regurgitation.

Thus, rheumatic valve disease and endocarditis appear to be the most common causes of severe aortic regurgitation in this hospital based population. Furthermore, echocardiography is a sensitive non-invasive technique for determining the cause of aortic regurgitation and allows differentiation of valvular from root causes of aortic regurgitation.

Aortic regurgitation may be caused by valvular disease, aortic root disease, or a combination of both. Early reports showed that rheumatic and syphilitic involvement accounted for most patients with chronic aortic regurgitation. ${ }^{1}$ With the decline in the incidence of these two diseases, aortic regurgitation has become a condition with multiple causes, ${ }^{2}$ which include infective endocarditis, dissecting aneurysms, traumatic rupture, and prolapse of an aortic leaflet secondary to myxomatous degeneration. ${ }^{3}$

The cause of aortic regurgitation is not always apparent from clinical examination. In the past this information could be obtained at cardiac catheterisation. With the advent of echocardiography differentiation of the various causes is possible non-invasively. The purpose of this study was to compare echocardiography with angiography in determining the causes of aortic regurgitation.

\section{Patients and methods}

M mode and cross sectional echocardiograms in 43 consecutive patients undergoing aortic valve replace-

Accepted for publication 27 June 1983 ment for predominant aortic regurgitation were reviewed. The patients' ages ranged from 25 to 62 years. Patients with pressure gradients $>20 \mathrm{~mm} \mathrm{Hg}$ across the aortic valve as well as those with combined stenosis and regurgitation were excluded from the study.

\section{ECHOCARDIOGRAPHY}

$M$ mode echocardiography was performed in the supine and left lateral position using a Smith-Kline Ekoline 20A ultrasonoscope with $2.5 \mathrm{MHz}$ medium $(7.5 \mathrm{~cm})$ internally focused transducer. Permanent recordings were obtained with a Irex 101 continuous recorder.

Cross sectional echocardiography was performed using a Varian V-3000 phased array sector scanner. Figs. 1-5 were photographed from single frame vidcotape images. Complete cross sectional echocardiograms included (a) the parasternal long axis view to evaluate the aorta, the aortic valve, and the mitral valve; (b) parasternal short axis views at the level of the aortic and mitral valves; and (c) apical four chamber and apical two chamber long axis view. The echocardiograms were reviewed by three echocardiographers without knowledge of the clinical, catheterisation, or surgical findings. 
Rheumatic mitral valve disease-The $M$ mode and cross sectional echocardiographic features of rheumatic mitral valve disease have been described in detail. ${ }^{4}$ In brief, the criteria for $M$ mode echocardiography are (a) a thickened mitral leaflet; (b) a varying E-F slope; (c) parallel motion of both anterior and posterior leaflets during diastole; and (d) an enlarged left atrium. The cross sectional criteria are (a) thickened mitral leaflets with an obtuse angular bend of the anterior mitral leaflet in diastole and (b) a relatively stationary posterior mitral leaflet in the parasternal long axis view. In addition, aortic valve involvement is suggested echocardiographically by thickened leaflets with restricted motion in the setting of mitral valve involvement ${ }^{4}$ (Fig. 1).

Bicuspid aortic valve-The criteria for M mode rec-
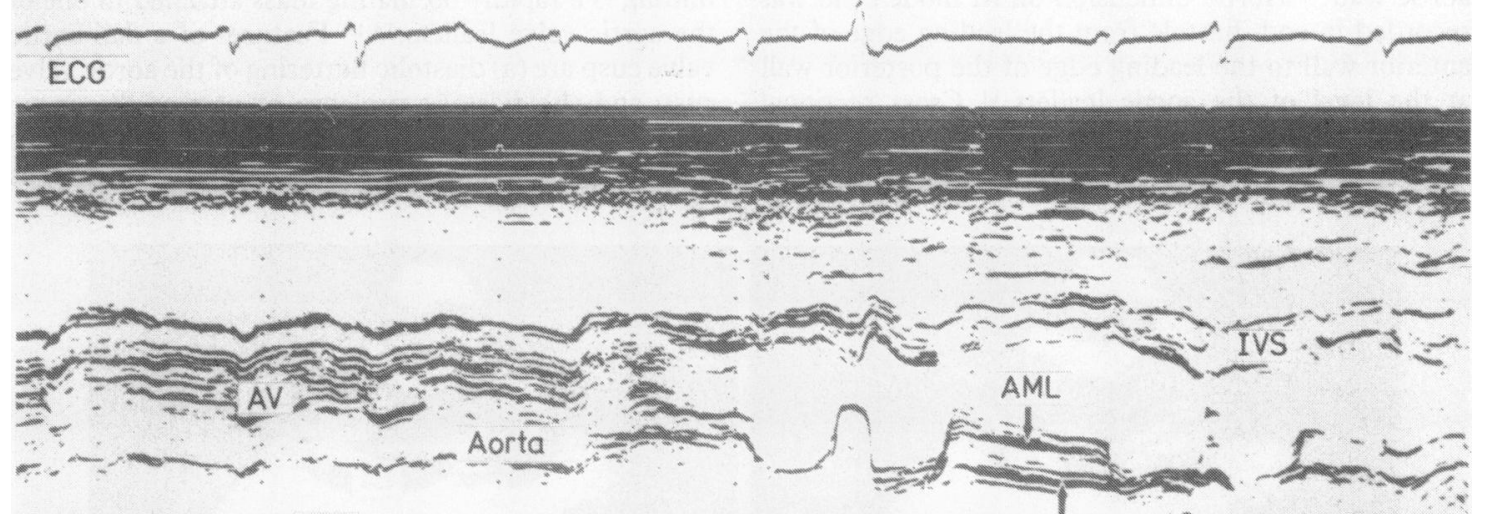

LA
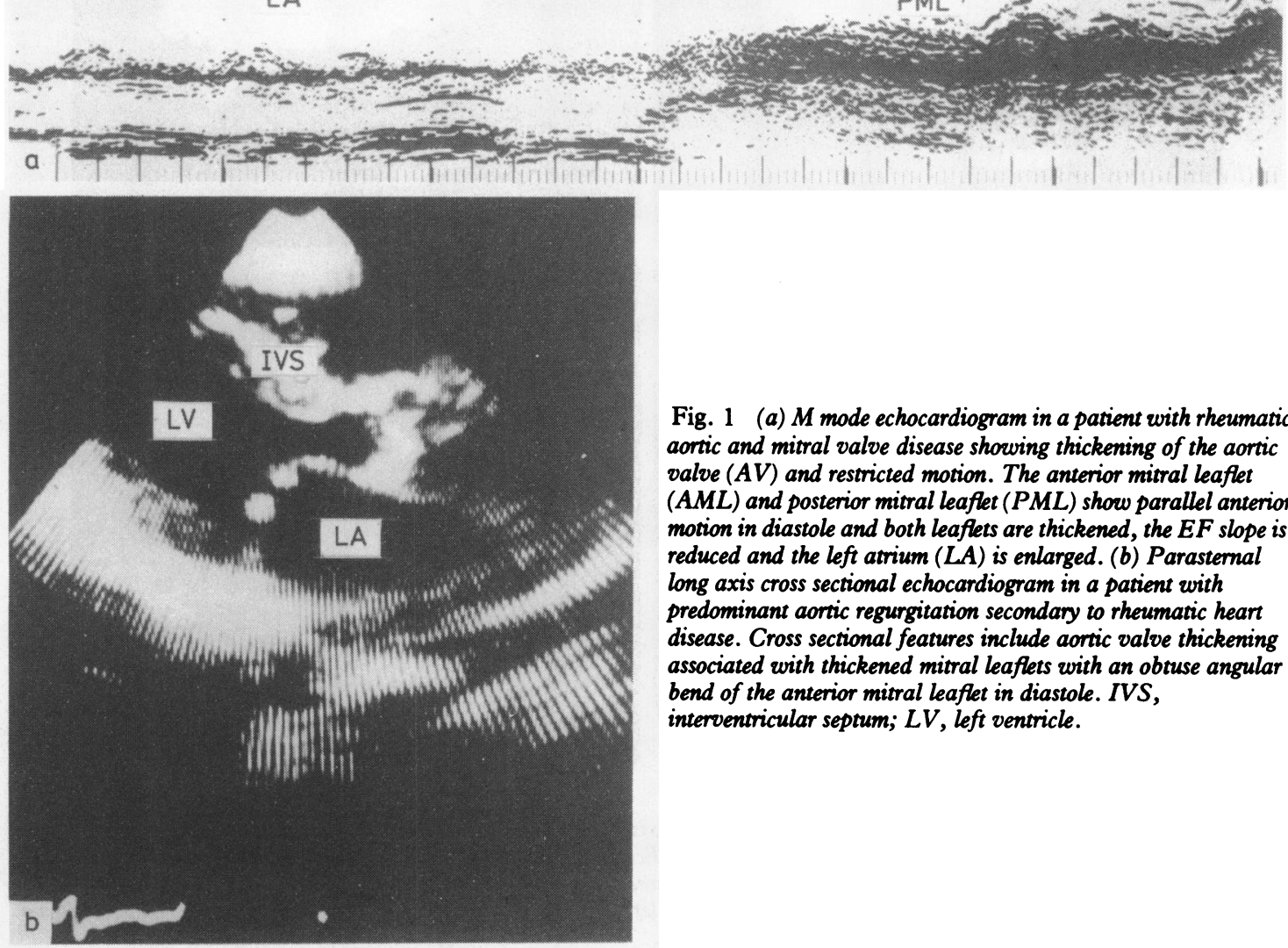

Fig. 1 (a) $M$ mode echocardiogram in a patient with rheumatic aortic and mitral valve disease showing thickening of the aortic valve $(A V)$ and restricted motion. The anterior mitral leaflet $(A M L)$ and posterior mitral leaflet $(P M L)$ show parallel anterior motion in diastole and both leaflets are thickened, the EF slope is reduced and the left atrium (LA) is enlarged. (b) Parasternal long axis cross sectional echocardiogram in a patient with predominant aortic regurgitation secondary to rheumatic heart disease. Cross sectional features include aortic valve thickening associated with thickened mitral leaflets with an obtuse angular bend of the anterior mitral leaflet in diastole. IVS, interventricular septum; $L V$, left ventricle. 
ognition of bicuspid aortic valve are an eccentricity index $\geqslant 1.5,56$ increased leaflet thickness, ${ }^{7}$ and multiple diastolic cusp echoes. ${ }^{68-10}$ The cross sectional echocardiographic findings of a bicuspid valve are two cusps seen on short axis view (with or without a raphe) ${ }^{9}$ and doming of the valves in systole in the parasternal long axis view 10 (Fig. 2)

Aneurysms-These were defined by both echocardiographic procedures as a localised dilatation of the aortic wall. ${ }^{11}$ Aortic dimension on $M$ mode echo was recorded in end diastole from the leading edge of the anterior wall to the leading edge of the posterior wall at the level of the aortic leaflets. ${ }^{11}$ Cross sectional measurement of the ascending aorta was made at the level of the midpoint of the sinuses of Valsalva in the parasternal long axis view. Aortic root dilatation was defined as $\geqslant 44 \mathrm{~mm} .^{11}$

Aortic valve vegetation-The $M$ mode echocardiographic features are (a) a rapidly oscillating density attached to one of the aortic leaflets causing a shaggy "thick" appearance of the aortic leaflets during systole and diastole 12 and (b) normal systolic motion or separation of the aortic valve leaflets (usually more than $2.5 \mathrm{~cm}$ ). The cross sectional echocardiographic finding is a rapidly oscillating mass attached to one of the aortic valve leaflets. ${ }^{1314}$ Features of a flail aortic valve cusp are (a) diastolic fluttering of the aortic valve cusp and (b) diastolic prolapse of part of the aortic valve leaflet into the left ventricle. ${ }^{15-18}$ A flail cusp may coexist with a vegetation or may occur by itself as
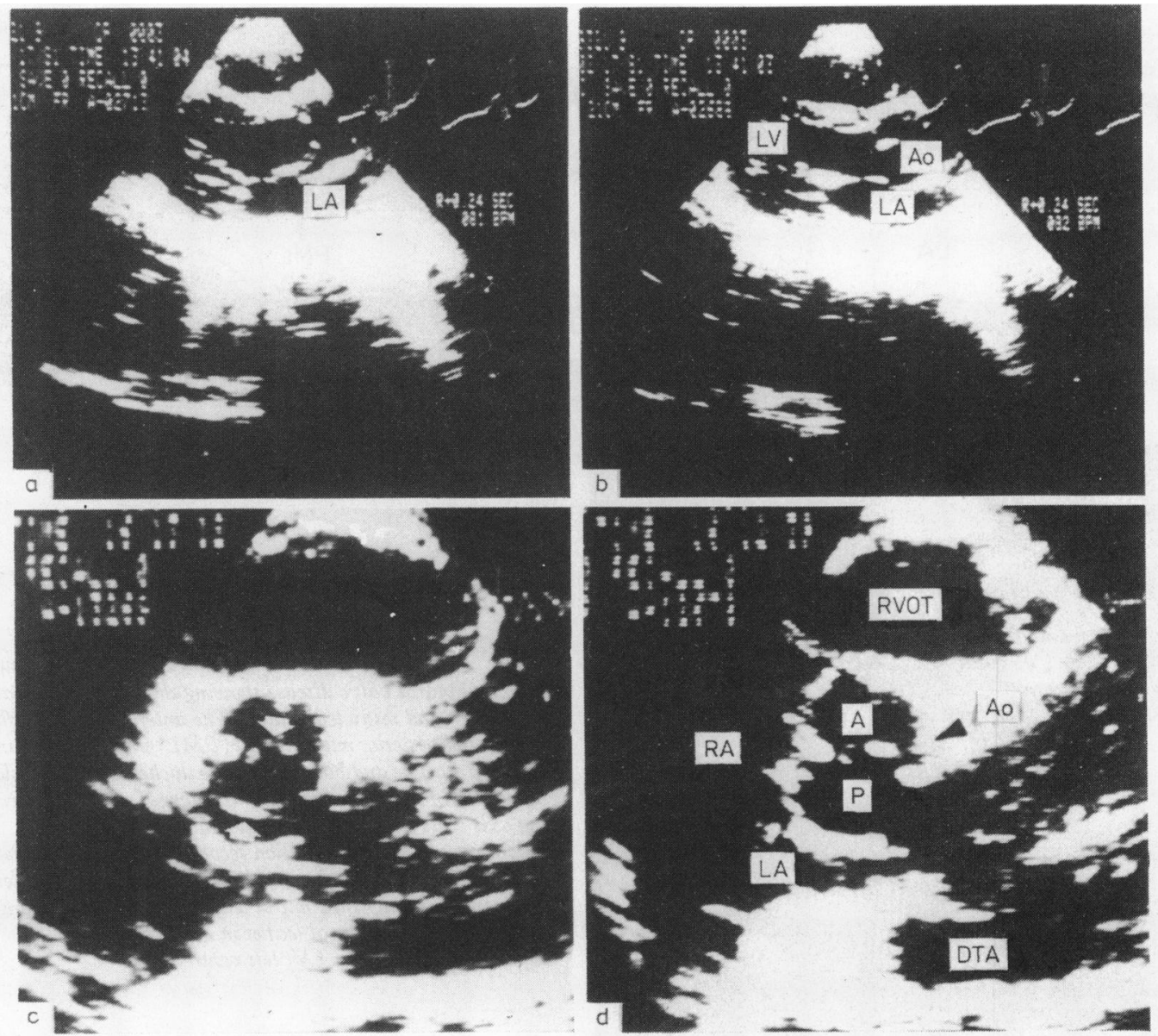

Fig. 2 Cross sectional echocardiogram in the parasternal long axis plane ( $a$ and $b$ ) and parasternal short axis plane (c and d) in a patient with a bicuspid aortic valve and aortic regurgitation. Systolic doming is apparent in $(a)$ with normal diastolic closure in (b). In the short axis view in systole the "circle within the circle" appearance is present in $(c)$ whereas in diastole $(d)$ the anterior $(A)$ and posterior $(P)$ cusps are separated by a horizontal commissure. LA, left atrium; Ao, aorta; $L V$, left ventricle; RVOT, right ventricular outflow tract; $R A$, right atrium; DTA, descending thoracic aorta. 
indicated by normal leaflet thickness. The distinction between a vegetation prolapsing into the outflow tract and a flail aortic valve leaflet may not always be made by cross sectional echocardiography.

\section{CARDIAC CATHETERISATION AND ANGIOGRAPHY}

All patients underwent complete left and right heart catheterisation percutaneously through the femoral artery and vein or through a cutdown to the right brachial artery and vein. Pressures were recorded with fluid filled manometers on an Electronics for Medicine photographic recorder. Left ventriculography was performed in the right anterior oblique and the left anterior oblique projections. Aortography was performed in the left anterior oblique projection or using biplane cineangiography in the right anterior oblique and left anterior oblique projections. The degree of aortic regurgitation was graded according to the method of Hunt $(1+$ to $5+) .{ }^{19}$ Twenty three patients had grade 5+ aortic regurgitation (radio opaque material completely opacified in the left ventricle in three or less beats with the aorta being denser than the ventricle) and 20 grade 4+ (opacification of the left ventricular cavity from the regurgitant flow with more than three beats). The angiograms were reviewed by two angiographers without knowledge of the clinical, echocardiographic, and surgical findings.

\section{DIAGNOSTIC CRITERIA}

Catheterisation and angiographic criteria for rheumatic aortic regurgitation include the presence of aortic regurgitation with a normal aortic root together with haemodynamic evidence of an end diastolic gradient across the mitral valve. A bicuspid aortic valve was present if only two cusps were identified on aortography. Aortic aneurysms were identified as localised dilatation or a diffuse enlargement of the aortic root on aortogram. The diagnosis of endocarditis by angiography was suggested if aortic valve vegetations, aortic root abscess, or sinus of Valsalva aneurysms were identified. Aortic valve vegetations were defined by angiography when localised radiolucencies were seen to move freely with the motion of the aortic valve leaflets or when localised filling defects were seen in the aortic sinus of Valsalva in the absence of calcification. These were frequently recognised during left ventriculography when simultaneous opacification of the left ventricle and aorta were seen.

\section{SURGERY}

Surgical and pathological confirmation were available in all patients. Aortic regurgitation was considered rheumatic in origin if fused commissures with calcified thickened and fibrosed valves with rolled up edges were present in association with mitral valve involvement-namely, cuspal, chordal, or commis- sural fusion. The mitral valve was inspected at the time of surgery by the surgeon. After the aortic root was opened and the aortic valve excised the left ventricular inflow tract to the left ventricular apex was inspected with the use of a head lamp. Rheumatic mitral valve involvement could be determined by direct visualisation of the deformed and thickened mitral leaflet. Aortic regurgitation was considered to be secondary to a biscuspid valve if two commissures were identified with or without a raphe present in one of the cusps. ${ }^{20}$ This cause was considered secondary to endocarditis if the aortic cusps were covered with multiple polypoid appearing vegetations or if the leaflet was perforated or torn in the presence of a clinical picture consistent with endocarditis. Healed endocarditis was considered to be present if there was thickening of the valve with adhesions, especially in patients with a past history or clinical syndrome compatible with endocarditis. Aortic regurgitation secondary to aortic root disease was present if pronounced generalised dilatation of the aorta was noted or if an aneurysm was present. Aneurysms are defined as a localised dilatation of the aortic wall and may be fusiform or saccular in configuration. Anuloaortic ectasia was defined as dilatation limited to the sinuses of Valsalva or pear shaped ectatic enlargement of the aortic root and ascending aorta. ${ }^{21}$ The two techniques, angiography and echocardiography, were compared in their ability to determine the cause of aortic regurgitation using surgical findings or necropsy findings as the standard of reference.

\section{Results}

The Table shows the causes of aortic regurgitation, as determined by anatomical inspection at surgery, echocardiography, and angiography.

\section{CAUSES}

Rheumatic heart disease-Seventeen patients had predominant aortic regurgitation secondary to rheumatic disease. Both $\mathbf{M}$ mode and cross sectional echocardiographic findings were consistent with rheumatic heart disease in all 17 patients. In each patient angiography showed 4+ to $5+$ aortic regurgitation, and end diastolic pressure gradients were recorded across the mitral valve.

Bicuspid aortic valve-Five patients had bicuspid aortic valves at surgery. Four had clinical presentations compatible with endocarditis. Echocardiographic findings were diagnostic of bicuspid valve in three patients by cross sectional echocardiography (Fig. 2). Echocardiography detected vegetations in three of four patients with endocarditis and a bicuspid valve. Three patients were considered to have bicuspid aortic valve by angiography. Fig. 3 shows the 
Table Causes of aortic regurgitation determined at surgery and by echocardiography and angiography

\begin{tabular}{llcr}
\hline Causes & \multicolumn{2}{l}{ No (\%) of patients correctly identified } & \\
\cline { 2 - 4 } & Surgery & Echocardiography & Angiography \\
\hline Rheumatic valve disease & 17 & $17(100)$ & $17(100)$ \\
Aortic root dilatation & 8 & $8(100)$ & $8(100)$ \\
Endocarditis (excluding bicuspid valves) & 13 & $8(62)$ & $8(62)$ \\
Bicuspid valve & $5^{\star}$ & $3(60)$ & $3(60)$ \\
Total & 43 & $36(84)$ & $36(84)$ \\
\hline
\end{tabular}

^Four with clinical presentation consistent with endocarditis.

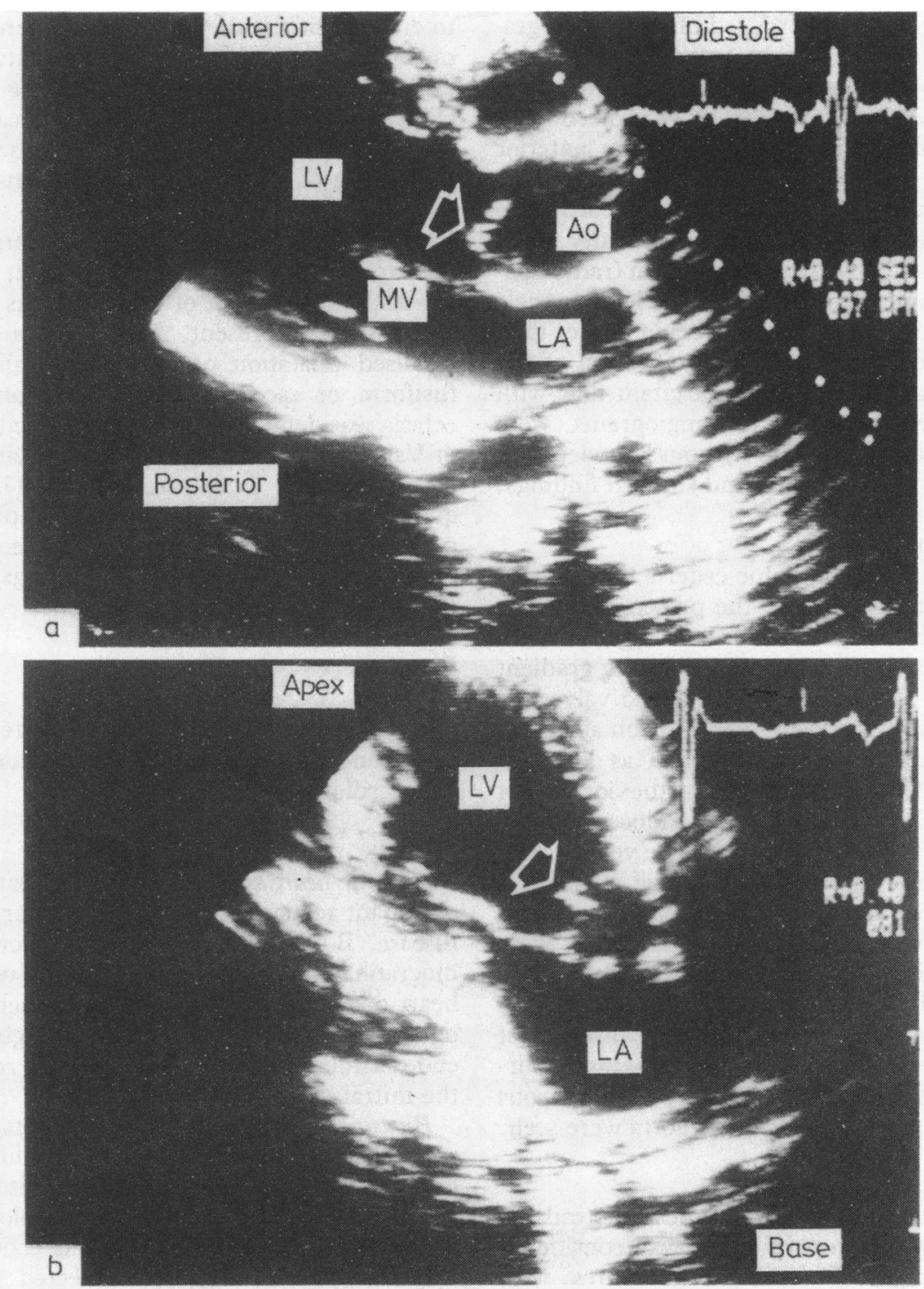

Fig. 3 Cross sectional echocardiogram showing (a) parastermal long axis view and (b) apical two chamber view in a patient with a bicuspid aortic valve and endocarditis. The aortic valve prolapses into the left ventricular outflow tract during diastole and is thickened (large arrow). In the two chamber apical view a small vegetation is attached to the anterior cusp and protrudes into the left ventricular outflow tract (large arrow). LA, left atrium; $L V$, left ventricle; Ao, aorta; $M V$, mitral valve. 
echocardiogram of a patient with bicuspid aortic valve and endocarditis.

Aortic root dilatation-Eight patients with severe aortic regurgitation had aneurysmal aortic root dilatation at surgery. Of these, six had typical anuloaortic ectasia (Fig. 4). Cross sectional echocardiography detected aortic root dilatation in all eight cases and $M$ mode detected the abnormality in five. In all patients, angiography reliably detected aortic root aneurysmal dilatation.

Endocarditis (excluding bicuspid valve)-Thirteen patients had aortic regurgitation secondary to endocarditis without bicuspid valves. One patient also had hypertrophic obstructive cardiomyopathy. Eight patients had a history of recent intravenous drug abuse. Patients with vegetations on other valves were not included in the study. Eight patients had cross sectional echocardiographic findings consistent with vegetations or prolapsed aortic valves; the remaining five patients had thickened valves without vegetations. These findings were confirmed at surgery. In all eight patients $M$ mode echocardiography showed a

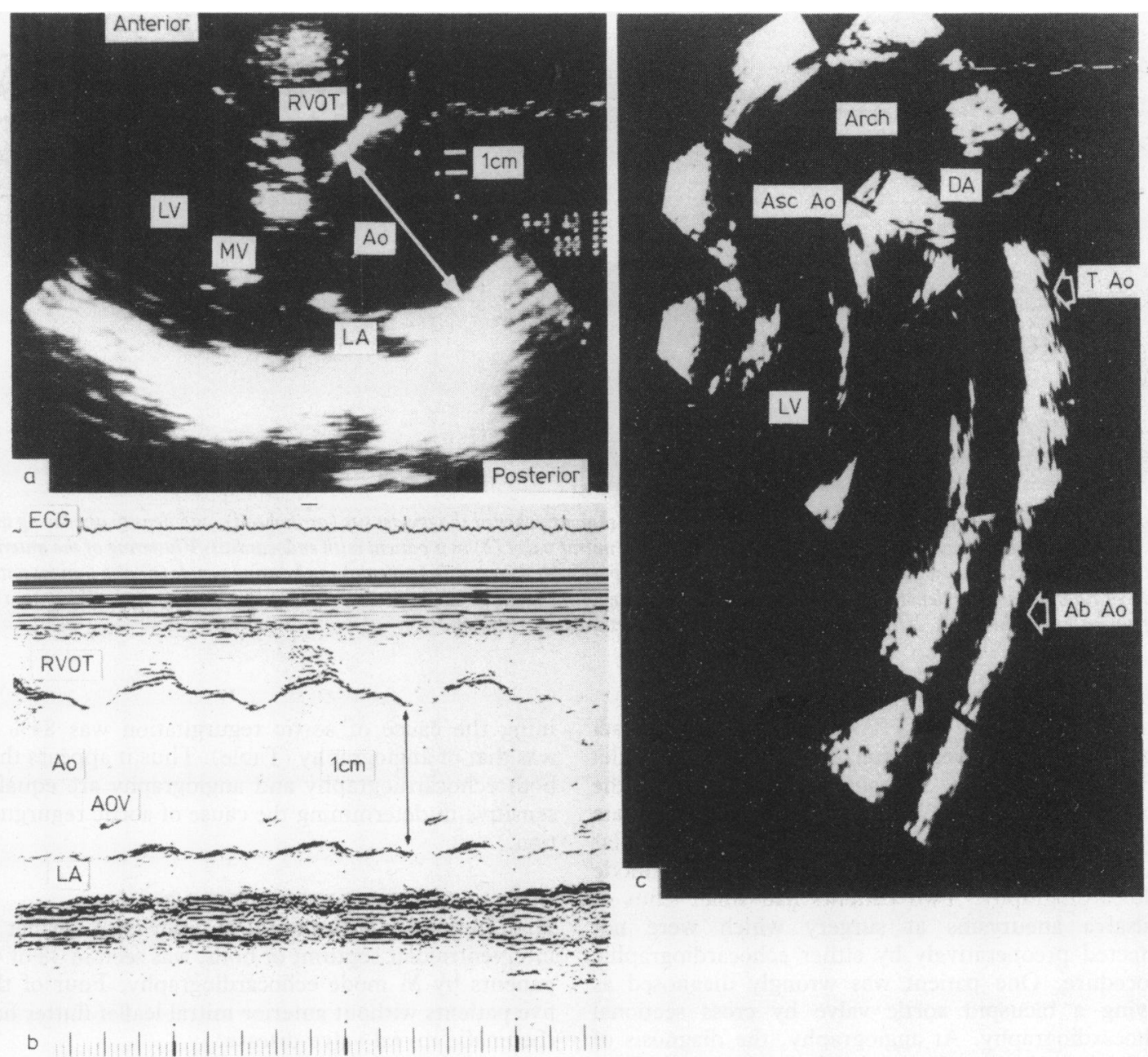

Fig. 4 (a) Cross sectional and (b) M mode echocardiograms in a patient with anuloaortic ectasia and (c) reconstructed view of the entire thoracic aorta obtained from multiple transducer positions and imaging planes in the same patient with anuloaortic ectasia. The ascending aorta (obtained from the parasternal right position), and the aortic arch (obtained from the suprasternal position), are grossly enlarged and ectatic. The descending thoracic aorta (obtained from the suprasternal position and off axis parasternal apical view) and the abdominal aorta (from the subcostal position) are of normal calibre. Ao, aorta; LA, left atrium; $M V$, mitral valve; $L V$, left ventricle; RVOT, right ventricular outflow tract; Asc Ao, ascending aorta; DA, descending aorta; TAo, thoracic aorta; Ab Ao, abdominal aorta. 


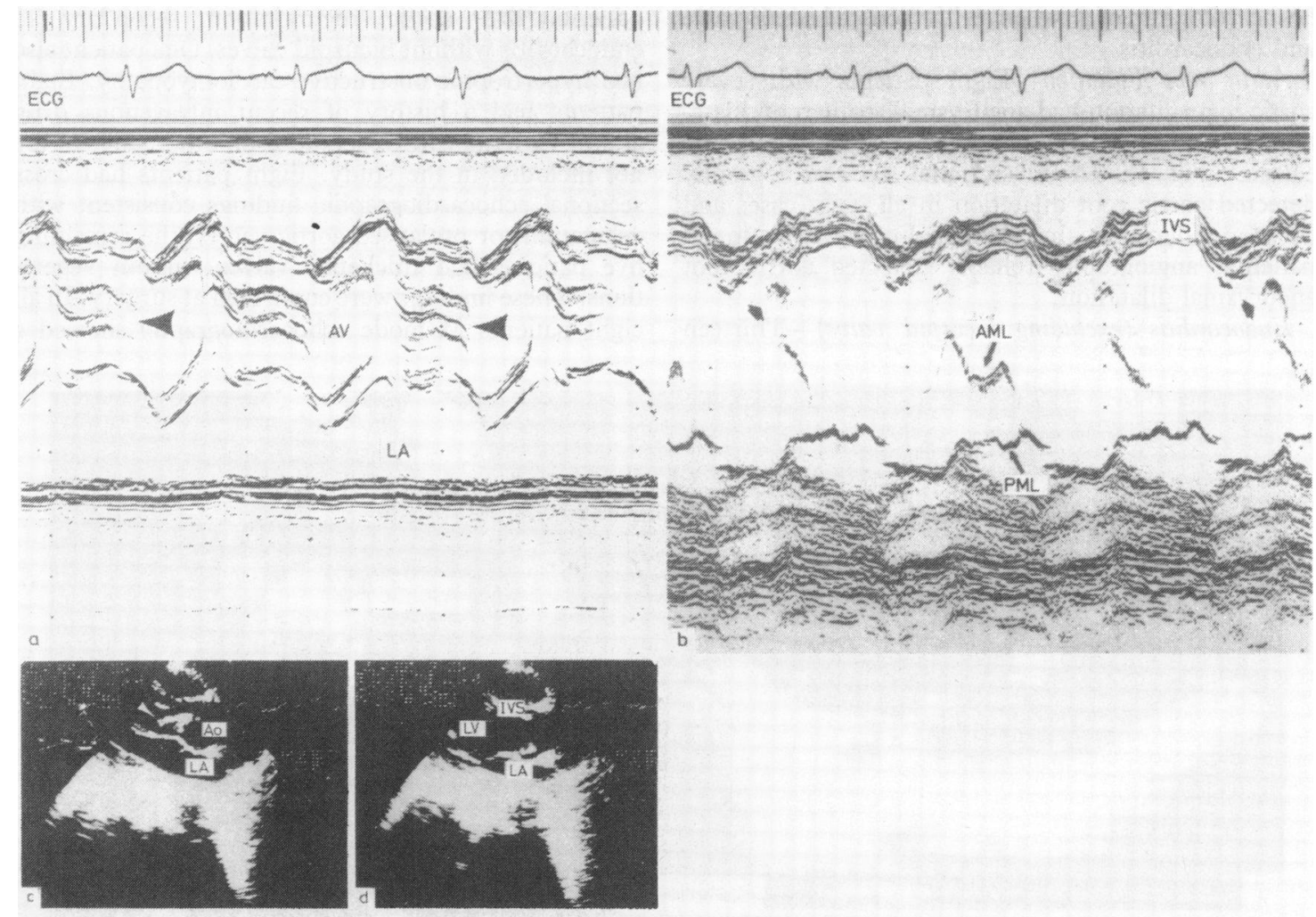

Fig. 5 (a) M mode echocardiogram of the aortic valve (AV) shows thickened shaggy density (arrowhead), and density appearing in the left ventricular outflow tract (arrowhead) at the level of the mitral valve (b) in a patient with endocarditis. Fluttering of the anterior mitral leaflet (AML) is also seen. (c) Cross sectional long axis parasternal view during diastole and during systole (d) of a patient with endocarditis: arrowhead denotes a structure prolapsing into the left ventricular outflow tract. At surgery a flail aortic leaflet with a vegetation was found. $L A$, left atrium; Ao, aorta; IVS, interventricular septum.

mass prolapsing in the left ventricular outflow tract consistent with a vegetation or a flail aortic leaflet (Fig. 5). In addition, a shaggy echo attached to the aortic valve was seen. We were unable to differentiate a flail leaflet from a vegetation in the left ventricular outflow tract by either cross sectional or M mode echocardiography. Two patients had small sinus of Valsalva aneurysms at surgery which were not detected preoperatively by either echocardiographic procedure. One patient was wrongly diagnosed as having a bicuspid aortic valve by cross sectional echocardiography. At angiography, the diagnosis of vegetation was suggested in four patients. Three patients had findings consistent with complications of endocarditis: two with sinus of Valsalva aneurysms and one with prolapse of an aortic leaflet.

\section{SENSITIVITY}

The overall sensitivity of echocardiography in determ- ining the cause of aortic regurgitation was $84 \%$ as was that of angiography (Table). Thus it appears that both echocardiography and angiography are equally sensitive in determining the cause of aortic regurgitation.

\section{AORTIC REGURGITATION (M MODE)}

High frequency flutter of the anterior mitral leaflet or interventricular septum, or both, was seen in $\mathbf{3 8}$ of $\mathbf{4 3}$ patients by $M$ mode echocardiography. Four of the five patients without anterior mitral leaflet flutter had rheumatic mitral valve disease.

\section{Discussion}

The present study shows that echocardiography is a useful technique in determining the cause of severe aortic regurgitation. Although endocarditis can be 
reliably suspected on clinical grounds, endocardiography is useful in confirming the vegetation or diagnosing a flail leaflet. In addition, the identification of a bicuspid valve by echocardiography is helpful in evaluating patients with aortic regurgitation, especially when is is not suspected clinically.

In our series of 43 patients with predominant aortic regurgitation, rheumatic involvement accounted for $40 \%$ of patients, endocarditis for $30 \%$ ( $40 \%$ including healed endocarditis on bicuspid valves), and aortic root disease in $19 \%$ of patients. A recent report from the United Kingdom has shown a higher incidence of aortic root disorders $(31 \%)$ and a lower incidence of rheumatic valve disease $(23 \%)$ and infective endocarditis $(21 \%){ }^{22}$ In that series, however, endocarditis was equally distributed among bicuspid and tricuspid valves, whereas most aortic valves affected by endocarditis in our series were not bicuspid. This could be accounted for by the high incidence of intravenous drug abusers in our urban city hospital environment. In addition, the low incidence of rheumatic aortic involvement in subjects in the United Kingdom compared with our population group probably reflects differences in geographical and socioeconomic conditions.

The ability of echocardiography correctly to determine the cause of aortic regurgitation was similar to that of angiography. A study by Leech and coworkers $^{23}$ has shown that $M$ mode echocardiography can be helpful in determining the cause of aortic regurgitation in $90 \%$ of patients undergoing valve replacement when correlated with surgical and histological findings. Furthermore, $M$ mode echocardiography is useful in assessing left ventricular dimensions and volume overload patterns secondary to aortic regurgitation. It is also a sensitive technique in detecting aortic regurgitation because of its ability to detect high frequency diastolic fluttering of the left side of the interventricular septum or mitral leaflet, or both. Fine fluttering may not, however, be seen in all patients with aortic regurgitation. Aortography or Doppler echocardiography, or both, are more sensitive in detecting aortic regurgitation. ${ }^{24}$ Cross sectional echocardiography provides spatial orientation and visualisation of intracardiac structures in more than one plane and complements $M$ mode echocardiography.

With regard to rheumatic aortic regurgitation, both $M$ mode and cross sectional echocardiography were $100 \%$ sensitive in diagnosing rheumatic heart disease. In all instances, associated rheumatic mitral valve involvement was present. Echocardiography appears to be the method of choice for detecting rheumatic valvular involvement of the heart. ${ }^{4} \mathrm{We}$ found no difference between $M$ mode and cross sectional echocardiography in detecting endocarditis. The $M$ mode features of valvular vegetations have been previously described and consist of a non-uniform echo producing mass attached to a valve leaflet with unrestricted and often chaotic valve motion. ${ }^{12} \mathrm{M}$-mode echocardiography can reliably detect vegetations in patients with aortic endocarditis in up to $86 \%$ of patients, even in the presence of pre-existing valvular lesions, and may allow the identification of subsets of patients with high risk who may need early surgery. ${ }^{25}$ Cross sectional echocardiographic findings of vegetation include rapidly oscillating masses attached to or replacing normal valve tissue. ${ }^{13}$ As in the present study, both techniques were equally sensitive in detecting vegetations, ${ }^{14}$ although cross sectional echocardiography is more sensitive than $M$ mode echocardiography in detecting complications of endocarditis such as sinus of Valsalva aneurysms. ${ }^{14}$ In two of our patients with sinus of Valsalva aneurysms, however, both $M$ mode and cross sectional echocardiography did not detect the lesions.

$M$ mode echocardiographic features of aortic valvular prolapse have been described ${ }^{26} 27$ and include (a) abnormal diastolic echoes protruding into the left ventricular outflow tract and disappearing in systole, (b) location of abnormal echoes anterior to the anterior mitral leaflet and in close relation to the interventricular septum, (c) the abnormal left ventricular echoes can be traced into the aorta in continuity with the aortic valve, (d) well defined systolic oscillation of the aortic leaflets, and (e) multiple cusp echoes centrally positioned within the aortic root during diastole. In addition, the presence of diastolic fluttering of the aortic cusps suggests a fenestrated aortic leaflet. ${ }^{15-17}$ Although ruptured aortic leaflets occur uncommonly with myxomatous degeneration, aortic root dissection, or trauma, ${ }^{16}$ the most frequent entity associated with a flail aortic leaflet is endocarditis. Nevertheless, even though the true incidence of myxomatous degeneration of the aortic valve is presently unknown, it does exist pathologically. ${ }^{28}$ Severe aortic regurgitation has been reported in patients with myxomatous degeneration even though clinically it was unsuspected. ${ }^{26}$

Krivokapicw and coworkers ${ }^{16}$ reported that the distinction between a flail leaflet and a vegetation may be made by noting the location of the hinge point of the motion of the abnormal echoes into the left ventricular outflow tract on cross sectional echocardiography. In flail leaflets the hinge point was located at the aortic wall, whereas with vegetation the hinge point was at the edge of the aortic leaflets. We have not found this a useful sign and cannot differentiate flail aortic leaflet with or without vegetations from vegetations alone. Daset $a l .{ }^{17}$ have suggested that ruptured aortic leaflet is most likely when these findings occur in the absence of other data to support a diagnosis of recent or 
remote endocarditis. The differentiation is more than academic since vegetations alone have been shown to disappear with effective medical treatment, whereas patients with a flail aortic leaflet invariably require surgery. ${ }^{18}$

With improved image intensification systems in recent years and improved quality of cineangiograms, it is possible to identify localised radiolucencies that move freely with the aortic valve leaflets during systole and diastole. When noted in association with a history of infective endocarditis (and in the absence of calcification) these lucencies are diagnostic of vegetations. The lucencies can also be identified in the area of the aortic sinuses of Valsalva. The angiogram is superior to both $M$ mode and cross sectional echocardiography in detecting complications of endocarditis-namely, paravalvular leaks, mycotic aneurysms, ring abscesses, or fistulous tracts. ${ }^{29}$ In addition, cardiac catheterisation is helpful when more than one valve is infected. Although cross sectional echocardiography is an excellent method for detecting vegetations and is useful in the follow up of patients treated for infective endocarditis, angiography should be performed in all patients in whom surgery and replacement of the aortic valve is contemplated. In addition, by identifying the coronary anatomy and origin of the coronary arteries unforeseen complications at the time of aortic valve replacement may be avoided.

The present series confirms previous reports of the superiority of cross sectional echocardiography over $M$ mode in identifying bicuspid aortic valve. ${ }^{30}$ The potential clinical value of cross sectional echocardiography in diagnosing a bicuspid valve is, however, limited by the technical inability adequately to image the aortic valve leaflets in many patients. ${ }^{31}$ Valve cusps may not always be visualised from the parasternal short axis view and an anteriorly tilted apical four chamber view has been recommended. ${ }^{31}$ Dense calcification may interfere with the determination of the number of cusps. In our series one of five patients with a bicuspid valve did not have a history of endocarditis. Although primary aortic regurgitation without infective endocarditis has been said to be uncommon, ${ }^{20}$ it may occur more frequently than is recognised. ${ }^{32} 33$ In one series from the United Kingdom, $15 \%$ of cases of severe aortic regurgitation were due to bicuspid valves without bacterial endocarditis. ${ }^{22}$ Leech and coworkers ${ }^{34}$ have shown that an isolated ejection sound, coinciding with final halting of the aortic valve cusp, is an accurate diagnostic sign of a bicuspid valve. Therefore, cross sectional echocardiography and angiography are not necessary for identifying bicuspid valves especially if combined $M$ mode echophonocardiographic findings are diagnostic.

Aortic root dilatation is an important cause of aortic regurgitation. DeMaria and coworkers ${ }^{11}$ have shown that cross sectional echocardiography is more accurate than $M$ mode echocardiography in detecting and locating aneurysms of the ascending aorta. Using cross sectional echocardiography we were able to identify all patients with aortic regurgitation secondary to aortic root dilatation and determine the degree of aortic root ectasia. M mode echocardiography is valuable in detecting aortic root dilatation sufficient to produce regurgitation without cusp abnormality; however, the entire proximal aorta is not always visualised. Echocardiography and angiography do not show correlations between the size of the aneurysm and degree of aortic regurgitation in patients with anuloaortic ectasia. ${ }^{21}$ Although we did not include in our study patients with acute aortic dissection and secondary aortic regurgitation, the cross sectional technique is superior to that of the $M$ mode in identifying this problem. ${ }^{35}$

Rare causes of aortic regurgitation may be detected by echocardiography. A myxoma may present clinically as rheumatic heart disease or endocarditis and produce aortic regurgitation from distention of the aortic root caused by downward movement of the myxoma. ${ }^{36}$ Aortic regurgitation may be present in what appears to be the clinical setting of endocarditis (constitutional symptoms including fever and myalgias); nevertheless, the cause may subsequently prove to be aortic root dilatation as a manifestation of rheumatic collagen vascular disorders such as giant cell arteritis. ${ }^{37}$

The severity of aortic regurgitation can be determined by non-invasive techniques. ${ }^{38} 39$ The echocardiographic measurement of left ventricular dimension is useful in assessing the severity of aortic regurgitation. With increasing severity of aortic regurgitation, there was progressive enlargement of left ventricular dimensions. ${ }^{38}$ In addition, echocardiographically determined stroke volume increased with the severity of aortic regurgitation. Henry and coworkers ${ }^{40}$ found a higher risk of perioperative complications and postoperative deaths from congestive heart failure in patients with aortic regurgitation and a left ventricular end systolic dimension $>55 \mathrm{~mm}$ or left ventricular fractional shortening of less than $25 \%$. They have advocated following patients with aortic regurgitation with serial $M$ mode echocardiograms. In the absence of symptoms, surgery has been recommended when the left ventricular end systolic dimension has increased beyond $55 \mathrm{~mm}$ or left ventricular fractional shortening of less than $25 \%$ has occurred. ${ }^{41}$ Recent data, however, reported by Fioretti et al. ${ }^{42}$ do not support the recommendations of Henry and coworkers. In their series of patients with aortic regurgitation a preoperative end systolic dimension $>55 \mathrm{~mm}$ did not preclude successful aortic valve replacement. 
In addition, long term survival was not affected, symptomatic relief occurred, and normalisation of left ventricular dimensions were recorded by $M$ mode echocardiography.

In conclusion, while $M$ mode echocardiography may provide useful information with regard to the severity of aortic regurgitation, both $M$ mode and cross sectional echocardiography can reliably determine the cause of aortic regurgitation. It appears that echocardiography is as sensitive as angiography in this respect. Angiography appears, however, to be superior to echocardiography in detecting small sinus of Valsalva aneurysms and aortic root abscesses, both of which can occur after bacterial endocarditis. In our institution rheumatic involvement accounted for $40 \%$ of patients with aortic regurgitation, endocarditis for $30 \%$ ( $40 \%$ including healed endocarditis on bicuspid valve), and aortic root disease for $19 \%$.

\section{References}

1 Hurst JW, ed. Valvular heart disease. In: The heart. 4th ed. New York: McGraw-Hill, 1978: 1022.

2 Fowler NO. Cardiac diagnosis and treatment. 2nd ed. Hagerstown: Harper and Row, 1976: 509.

3 Morganroth J, Perloff JK, Zeldis SM, Dunkman WB. Acute severe aortic regurgitation. Pathophysiology, clinical recognition, and management. Ann Intern Med 1977; 87: 223-32.

4 Kotler MN, Mintz GS, Parry WR, Segal BL. M-mode and twodimensional echocardiography in mitral and aortic regurgitation. Pre and postoperative evaluation of volume overload of the left ventricle. Am 7 Cardiol 1980; 46: 1144-52.

5 Nanda NC, Gramiak R, Manning J, Mahoney EB, Lipchik EO, DeWeese JA. Echocardiographic recognition of the congenital bicuspid aortic valve. Circulation 1974; 49: 870-5.

6 Radford DJ, Bloom KR, Izukawa T, Moes CAF, Rowe RD. Echocardiographic assessment of bicuspid aortic valves. Circulation 1976; 53: 80-5.

7 Williams RG, Tucker CR. Echocardiographic diagnosis of congenital heart disease. Boston: Little and Brown, 1977:171-8.

8 Feigenbaum H. Echocardiography. 3rd ed. Philadelphia: Lea and Febiger, 1981:350-2.

9 Kotler MN, Mintz GS, Parry WR, Segal BL. Two-dimensional echocardiography in congenital heart disease. Am $\mathcal{f}$ Cardiol 1980; 46: $1237-46$.

10 Weyman AE, Feigenbaum H, Dillon JC, Chang S. Crosssectional echocardiography in assessing the severity of valvular aortic stenosis. Circulation 1975; 52: 828-34.

11 DeMaria AN, Bommer W, Neumann A, Weinert L, Bogren H, Mason DT. Identification and localization of aneurysms of the ascending aorta by cross-sectional echocardiography. Circulation 1979; 59: 755-61.

12 Dillon JC. Echocardiography in valvular vegetations. Am $\mathcal{F}$ Med 1977; 62: 856-62.

13 Gilbert BW, Haney RS, Crawford F, et al. Two-dimensional echocardiographic assessment of vegetative endocarditis. Circulation 1977; 55: 346-53.

14 Mintz GS, Kotler MN, Segal BL, Parry WR. Comparison of two-dimensional and $M$-mode echocardiography in the evaluation of patients with infective endocarditis. Am F Cardiol 1979; 43: 738-44.

15 Ramierez J, Guardiola J, Flowers NC. Echocardiographic diagnosis of ruptured aortic valve leaflet in bacterial endocarditis. Circulation 1978; 57: 634-6.

16 Krivokapicw J, Child JS, Skorton DJ. Flail aortic valve leaflets: $M$-mode and two-dimensional echocardiographic manifestations. Am Heart I 1980; 99: 425-37.

17 Das G, Lee CC, Weissler AM. Echocardiographic manifestations of ruptured aortic valvular leaflets in the absence of valvular vegetations. Chest 1977; 72: 464-8.
18 Chandraratna PAN, Robinson MJ, Byrd C, Pitha JV. Significance of abnormal echoes in the left ventricular outflow tract. Br Hean f 1977; 39: 381-9.

19 Hunt $D$, Baxley WA, Kennedy JW, Judge TP, Williams JE, Dodge HT. Quantitative evaluation of cineaortography in the assessment of aortic regurgitation. Am $\mathcal{J}$ Cardiol 1973; 31: 696-700.

20 Fenoglio JJ Jr, McAllister HA Jr, DeCastro CM, Davia JE, Cheitlin MD. Congenital bicuspid aortic valve after age $20 . A m \mathcal{F}$ Cardiol 1977; 39: 164-9.

21 Lemon DK, White CW. Anuloaortic ectasia: angiographic, hemodynamic and clinical comparison with aortic valve insufficiency. Am $\mathcal{F}$ Cardiol 1978; 41: 482-6.

22 Davies MJ, Brooksby I, Leech GJ, Parker J, Braimbridge MV. Pathology of aortic regurgitation[Abstract]. Br Heart $\mathcal{F} 1978 ; 40$ : 460.

23 Leech GJ, Davies MJ, Brooksby I, Parker J, Braimbridge MV. Use of M-mode echocardiography to determine pathogenesis of aortic regurgitation [Abstract]. Br Heart $\mathcal{f}$ 1978; 40: 460.

24 Esper RJ. Detection of mild aortic regurgitation by range-gated Doppler echocardiography. Am f Cardiol 1982; 50: 1037-43.

25 Hickey AJ, Wolfers J, Wilcken DEL. Reliability and clinical relevance of detection of vegetations by echocardiography in bacterial endocarditis. $\mathrm{Br}$ Hear $\mathcal{f} 1981 ;$ 46: 624-8.

26 Rodger JC, Morley P. Abnormal aortic valve echoes in mitral prolapse. Echocardiographic features of floppy aortic valve. $\mathrm{Br}$ Hear f 1982; 47: 337-43.

27 Olsen EGJ, Al-Rufaie HK. The floppy mitral valve. Study on pathogenesis. $\mathrm{Br}$ Heart $\mathcal{f}$ 1980; 44: 674-83.

28 El Shahawy ME, Graybeal R, Pepine CJ, Conti CR. Diagnosis of aortic valvular prolapse by echocardiography. Chest 1976; 69: 411-3.

29 Welton DE, Young JB, Raizner AE, et al. Value and safety of cardiac catheterization during active infective endocarditis. Am $\mathcal{f}$ Cardiol 1979; 44: 1306-10.

30 Fowles RE, Martin RP, Abrams JM, Schapira JN, French JW, Popp RL. Two-dimensional echocardiographic features of bicuspid aortic valve. Chest 1979; 75: 434-40.

31 Zema MJ, Caccavano M. Two-dimensional echocardiographic assessment of aortic valve morphology: feasibility of bicuspid valve detection. Prospective study of 100 adult patients. $\mathrm{Br}$ Heart f 1982; 48: 428-33.

32 Roberts WC, Morrow AG, McIntosh CL, Jones M, Epstein SE. Congenitally bicuspid aortic valve causing severe, pure aortic regurgitation without superimposed infective endocarditis. Am $\mathcal{F}$ Cardiol 1981; 47: 206-9.

33 Mills $P$, Leech G, Davies $M$, Leatham $A$. The natural history of a non-stenotic bicuspid aortic valve. Br Heart f 1978; 40: 951-7.

34 Leech G, Mills $P$, Leatham A. The diagnosis of a non-stenotic bicuspid aortic valve. $B r$ Heart $\mathcal{f} 1978 ; 40$ : 941-50.

35 Victor MF, Mintz GS, Kotler MN, Wilson AR, Segal BL, Parry WR. Two-dimensional echocardiographic diagnosis of aortic dissection. Am 7 Cardiol 1981; 48: 1155-9.

36 Bourdillon PDV, Monro JL, Johnson AM. Left atrial myxoma with aortic regurgitation. Br Heart $\mathcal{F}$ 1978; 40: 575-8.

37 How J, Strachan RW. Aortic regurgitation as a manifestation of giant cell arteritis. Br Heart f 1978; 40: 1052-4.

38 Gray KE, Barritt DW. Echocardiographic assessment of severity of aortic regurgitation. Br Heart $\mathcal{F}$ 1975; 37: 691-9.

39 Thompson R, Ross I, Elmes R. Quantification of valvular regurgitation by cardiac gated pool imaging. $\mathrm{Br}$ Heart $\mathcal{F}$ 1981; 46: 629-35.

40 Henry WL, Bonow RO, Borer JS, et al. Observations on the optimum time for operative intervention for aortic regurgitation. I. Evaluation of the results of aortic valve replacement in symptomatic patients. Circulation 1980; 61: 471-83.

41 Henry WL, Bonow RO, Rosing DR, Epstein SE. Observations on the optimum time for operative intervention for aortic regurgitation. II. Serial echocardiographic evaluation of asymptomatic patients. Circulation 1980; 61: 484-92.

42 Fioretti P, Roelandt J, Bos RJ, et al. Echocardiography in chronic aortic insufficiency. Is valve replacement too late when left ventricular end-systolic dimension reaches $55 \mathrm{~mm}$ ? Circulation 1983; 67: 216-21.

Requests for reprints to Dr Morris N Kotler, Likoff Cardiovascular Institute, Hahnemann University, 230 North Broad Street, Philadelphia, Pennsylvania 19102, USA. 